\title{
LA INFLUENCIA AFRICANA EN LA ICONOGRAFIA EQUINA DE LA VILLA DE AGUILAFUENTE (SEGOVIA)
}

\author{
M. ${ }^{a}$ Rosario LuCAS Pellicer
}

Los mosaístas africanos contribuyeron con su lozanía y creatividad a renovar la concepción del campo musivario, influyendo decisivamente a adecuar la temática al espíritu de la sociedad romana. Entre sus muchos logros se valora la incorporación de la iconografía circense al emblema de los pavimentos y su posterior difusión a otras provincias del Imperio.

Se puede discutir la prioridad de Cartago (1) en la narrativa del espectáculo (arquitectura y desarrollo de las carreras), pero no cabe duda de que los mosaicos africanos han proporcionado el mayor número de ejemplos sobre dos tipos de representaciones de larga pervivencia: a) el auriga victorioso (2); b) el corcel vencedor (3).

Ambos motivos, aislados o en conjunto, ya sea como tema singular o repetido, sugieren el arrojo en la competición y la gloria del triunfo, remarcada a su vez por la presencia de palmas, coronas u otros elementos alusivos al premio y la victoria.

\section{Iconografía de Equi Gircenses}

Cuando se representan cuádrigas o bigas, los caballos tienen tanto protagonismo como los conductores (4). Arnés y enjaezado, aparte de otros detalles (vendas en las patas, collares, adornos de plumas y cintas, marcas de cuadra o propietario...), la constancia de su nombre y muy especialmente la palma empenachando la cabeza (ocasionalmente en la cola) distinguen y enfatizan a estos animales some-

(1) Dunbabin, K. M.: The Mosaics of Roman North Africa. Studies in Iconography and Patronage. Oxford, 1978, cap. VI. Humphrey, J. H.: Roman Circuses. Arenas for Chariot Racing., London, 1986, pág. 177 y cap. 5.

(2) Dunbabin, K. M.: "The Victorius Charioteer on Mosaics and related Monuments" AJA, vol. 86, n. ${ }^{\circ} 1,1982$, págs. 65-89.

(3) Ennaïfer, M.: "Le theme des chevaux vainqueurs à travers la sèrie des mosaïques africaines». MEFR, t. 95 , 1983, págs. $817-858$.

(4) Humphrey: O. c. nota 1 hace notar que en Hispania y N. de Africa se da más importancia a los caballos que a los aurigas. El mosaico circense de Barcelona es un buen ejemplo. 
tidos a un duro entrenamiento con un fin muy concreto: competir y vencer en las carreras del hipódromo. Por esta razón la figura o figuras de los caballos vencedores (parte por el todo) condensa en su iconografía todas las connotaciones honoríficas y simbólicas expresadas en la narrativa de los ludi circenses o en el testimonio del auriga triunfante.

La tipología del caballo "honoré a la suite du succés dans l'arene» es agrupada por M. Ennaïfer en dos modelos (5):

a) Corcel aislado en cuadro geométrico o floral de tipo medallón. El esquema prototipo se localiza en el «Mosaico de los Caballos» de Cartago, auténtico repertorio de estas imágenes equinas, datado hacia el año $300 \mathrm{~d}$. C. (6).

b) Esquema tripartito formado por dos caballos afrontados, separados por una palmera o por el símbolo del premio. El documento más antiguo (inicios s. III) procede de Hadrumetum (Susa) y está representado en la mansión urbana de Sorothus famoso criador de caballos (7).

Entre los mosaicos hispanos el emblema portugués de Torre de Palma (Monforte), fechado entre los siglos III y IV (8) sigue el modelo a). La disposición de los cinco caballos (cuatro en las esquinas y uno central) se repite en el mosaico africano de Bulla Regia (en este caso con un auriga en medio) fechado en el s. IV (9). A estos cuadros se asemeja el corcel innominado de Libreros (Vejer, Cádiz) de cronología no muy posterior y galardonado con palma entre las orejas y, al igual que los portugueses, con marca de establo en el anca (10).

El modelo b), con palmera en el centro y ramas sobre las colas, se atestigua en dos ladrillos de la Bética (11), pero en los mosaicos que siguen este esquema (emblema de Aguilafuente y cuadrito sevillano de la calle Nueva de Santiponce) el árbol no es una palmera (12) ni los caballos ostentan el atributo del premio.

La intención de estas u otras imágenes semejantes, si se toma como apoyo las figuraciones africanas, responde, según Ennaïfer (13), a una doble motivación:

(5) Ennaïfer: O. c. nota 3, págs. 824 y 842.

(6) Salomonson, J. V.: Mosaique aux chevaux de l'Antiquarium de Carthage, The Hague, 1965.

(7) Foucher, L.: Inventaire des mosaĩques. "Feuille n. ${ }^{\circ} 57$ de L'Atlas archelogique. Sousse». Tunis, 1960. págs. 58-59 y lám. XXVII-XXX.

(8) Heleno, H.: "A vila lusitano-romana de Torre de Palma (Monforte)". O Arq. Port. ser. 2, 4, 1962, págs. 313 y ss. De Almeida, F.: "O mosaico dos cavalos" O Arq. Port., ser. 3, 4, 1970, págs. 263-275; ID, "Sur quelques mosaĩques du Portugal» en La mosaique grèco-romaine 2, París, 1975, págs. 219-226.

(9) Hanoune, R.: “Inventaire des mosaĩques de Bulla Regia», MEFR, n. ${ }^{\circ} 204,1969$, pág. 286; Ennaïfer: O. c., nota 3, pág. 829, figs. 12 y 13 .

(10) Blázquez, J. M.: Corpus de Mosaicos de España, Fasc. IV, Madrid, 1982, n. 50, págs. 53-56, lám. 42.

(11) Existe un mínimo de dos ejemplares idénticos. Uno está depositado en el Museo de Sevilla y otro en colección particular: P. de PALOL, Arqueología cristiana de la España Romana, Madrid-Valladolid, 1967, pág. 264 y lám. LX; Schlunk, H. und Hausild, T.: Die Denkmäler der frühchristlichen und westgotischen Zeit, Mainz, 1978, págs. 57-58 y lám. 72. El procedente de Osuna (col. particular) decoraría una casa privada. Fecha muy controvertida.

(12) Blanco, A.: Corpus de Mosaicos Romanos de España, Fasc. II (Italica I), Madrid, 1978, n. ${ }^{\circ}$ 16, pág. 38 y lám. 40. El dibujo del mosaico de Santiponce está incompleto, pero la disposición de los pájaros posados en las ramas y el cuadrito de la misma procedencia con perro y jabalí afrontados y separados por un elemento vegetal sugieren la existencia de una composición tripartita, posiblemente otro caballo simétrico al conservado. Sobre Aguilafuente vide infra.

(13) O. c., nota 3, pág. 843. 
1) Satisfacer a los seguidores de las facciones circenses que deseaban representar en sus mansiones las imágenes de sus caballos favoritos y campeones. Tal sería la interpretación del mosaico portugués que individualiza con los nombres y estampa física cada uno de estos animales.

2) Conjurar las fuerzas del mal contraponiendo a las asechanzas y maleficios el concepto general de la competición victoriosa. De este modo podría explicarse, en principio, el caballito de Vejer o los ladrillos de la Bética con animales sin nombre pero laureados.

¿Es válido hacer extensibles las mismas interpretaciones a otros caba'los que no exhiben explícitamente su gloria?

De todos es sabido que, en el mundo romano, la imagen del caballo, aparte de estar asociada a temas mitológicos y apotropaicos y testimoniar la popularidad y fervor por los juegos de circo, en el plano profano y religioso da cumplido testimonio de su servicio al hombre (14) y sobre todo ensalza al noble bruto indispensable en las grandes venationes, informando y reafirmando otros aspectos sociales y económicos nada desdeñables. Entre ellos la importancia de la cría y entrenamiento de los caballos. Este último aspecto, en mi opinión, no puede separarse completamente de la iconografía de los "caballos de circo" plasmada en diversos ejemplos de nuestro territorio y Norte de Africa.

\section{Los caballos en Aguilafuente}

La decoración (pintura mural y mosaico) de la villa de Aguilafuente (Segovia) cuya excavación (15) fue impulsada por D. Gratiniano Nieto, me permite formular una tercera hipótesis ampliando las conclusiones de Ennaïfer: La representación de corceles, premiados o no, ilustra el noble arte de la crianza e hipología y mediante sus imágenes los propietarios rurales informan de su condición y auguran la victoria de los ejemplares que, procedentes de sus cuadras, abastecian la constante demanda de buenos caballos y la costosa celebración de los juegos ecuestres (16).

(14) Amplia documentación en Vigneron, P.: Le Cheval dans l'Antiquité Gréco-romaine, 2 vols., Nancy, 1968.

(15)Lucas, R. y Viñas, V.: “La villa romana de Aguilafuente (Segovia) en Segovia y la Arqueología Romana, Univ. de Barcelona, 1977, pág. 239-255. La pintura mural restaurada y consolidada en el I.C.C.R.O.A., está depositada en el Museo Provincial de Segovia. Los mosaicos, en espera de su instalación definitiva, se guardan en el Ayuntamiento de Aguilafuente.

(16) Gorges, J. G.: En Les villes Hispano-Romaines, París, 1979, págs. 155-157 y passim considera que el cuidado de los caballos es ocupación personal del dominus y las muchas representaciones en las villae romanas traducen el pensamiento de los propietarios. En torno a los polos caballo, vino, caza y letras gravitaba la mentalidad de los latifundistas tomando como medida el paradigma imperial.

Esta información según DUNBABIN (O. c., nota 1, pág. 10 y cap. VII) es parte del espíritu de la sociedad africana, bien documentado en el realismo de las escenas rurales y en la temática del ciclo latifundista. Humphrey por su parte (O. c., nota 1, caps. 6 y 7) insiste en las muchas imágenes de caballos nominados que exhiben marca y nombre del propietario en los mosaicos de $\mathrm{N}$. de Africa e Hispania. Esta recurrencia es intencionada y refleja la relevancia económica y social de la cría de caballos, explicando asímismo la afición a las carreras y los numerosos testimonios directos e indirectos sobre la celebración de ludi circenses. El Mosaico de los Caballos de Cartago podría explicarse en este sentido de información de propietarios (págs. 305 y ss.); 
De la pintura mural (ala Norte del corredor) se ha conservado un fragmento del zócalo (lám. 1) que muestra, en dos paños centrales, distintas especies de aves posadas en ramajes y picoteando flores. A la izquierda, en panel distinto, se pintó un caballo de perfil marchando hacia la izquierda. Está contorneado en negro, es de pelaje grisáceo, cabeza grande, lomo curvo y sus patas en movimiento simulan un trote reposado alzando el brazuelo derecho ("a la española»). No se distingue ningún atributo especial y sólo se aprecia un cabezal muy simple (muserola y frontalera en rojo) y el inicio de un ronzal negro.

Salvando distancias técnicas y estéticas, la postura es la normal de la mayoría de los caballos aislados que repiten en su iconografía un viejo modelo consagrado en el famoso mosaico del Antiquarium de Cartago anteriormente citado. La composición, en conjunto, es comparable a escenas conocidas en mosaicos y pinturas que muestran diversos animales en libertad junto al edificio de la villa y sus dependencias, idílicamente envueltas en un ambiente paradisíaco (17); pero estos mismos motivos, máxime si los animales adoptan disposición heráldica, se utilizan en decoraciones domésticas y religiosas (tumbas y basílicas) como recurso simbólico para recabar la suerte y la fortuna (18) o como alegoría evocadora de bienaventuranza e inmortalidad (19).

El cualquier caso el significado de la pintura mural de Aguilafuente no debe desconectarse de la interpretación que se dé al mosaico del "oecus". Cronológicamente se plantean distancias en la ejecución pero ambas composiciones se mantuvieron hasta el ocaso de la villa (traspasado el s. IV) y el dibujo mural, con algunas correciones y distinto color, repasó figuras que ya existían con anterioridad.

El pavimento que aquí interesa ocupaba la habitación más espaciosa de la villa $\left(82,50 \mathrm{~m}^{2}\right)$. El conjunto responde al esquema del cuadriculado ortogonal con decoración múltiple (20) y el emblema, desplazado del eje central, abarca un cuadro de 2,90 m. de lado bordeado de trenza de dos cabos y enmarcado por un filete simple de teselas negras. En el campo blanco se representaron cuatro caballos y dos arbolillos contrapuestos, es decir, una doble pareja de équidos flanqueando un elemento vegetal, simétricamente dispuestos. Un dibujo realizado en 1868 (fig. 1) y enviado a la Real Academia de la Historia (21), da una visión más completa que lo conservado en la actualidad (fig. 2 y lám. II) y permite la reconstrucción teóri-

(17) Romanelli, P.: «Riflessi di vita locale nei mosaici africani» en la M. G. R., 1965, pág. 270. El ambiente de parque rodeando la villa (con o sin caballos) documentado en Tabarka, Oudna... En España se puede citar el emblema del corredor de la villa del Romeral (Lérida), la lápida sepulcral de Antonia Vetia (Itálica)... La documentación paleocristiana es pródiga en la adaptación de estas escenas. De Palol, P.: «En torno a la iconografía de los Mosaicos cristianos de las Islas Baleares", I. ${ }^{a}$ Reunión Nac. de Arq. Crist. (Vitoria, 1966), 1977, págs. 131-149.

(18) Dunbabin: O. c., nota 1, pág. 103 y cap. IX, especialmente, págs. 167-170, nota 17.

(19) Cummont, T.: Rechêrches sur le symbolisme funèraire des Romains, París, 1942. Toynbee, J. M. C.: "Life, Death and Afterlife on Roman Age Mosaics" en Jenseits Vorstellungen in Antike und Christentum (Fedenkschrift für A. Stuiber) Jahrb. Ant. und Christ., 1982, n. ${ }^{\circ}$ 9, págs. 210-214.

(20) Lancha, J.: Mosaiques Geometriques, Roma, 1977, cap. I.

(21) Exp. Antigüedades de Segovia. Agradecemos aquí el permiso para realizar la consulta y las reproducciones. 
FIG. 1.-Esquema del emblema de Aguilafuente (Segovia).

Según dibujo de la Real Academia de la Historia.
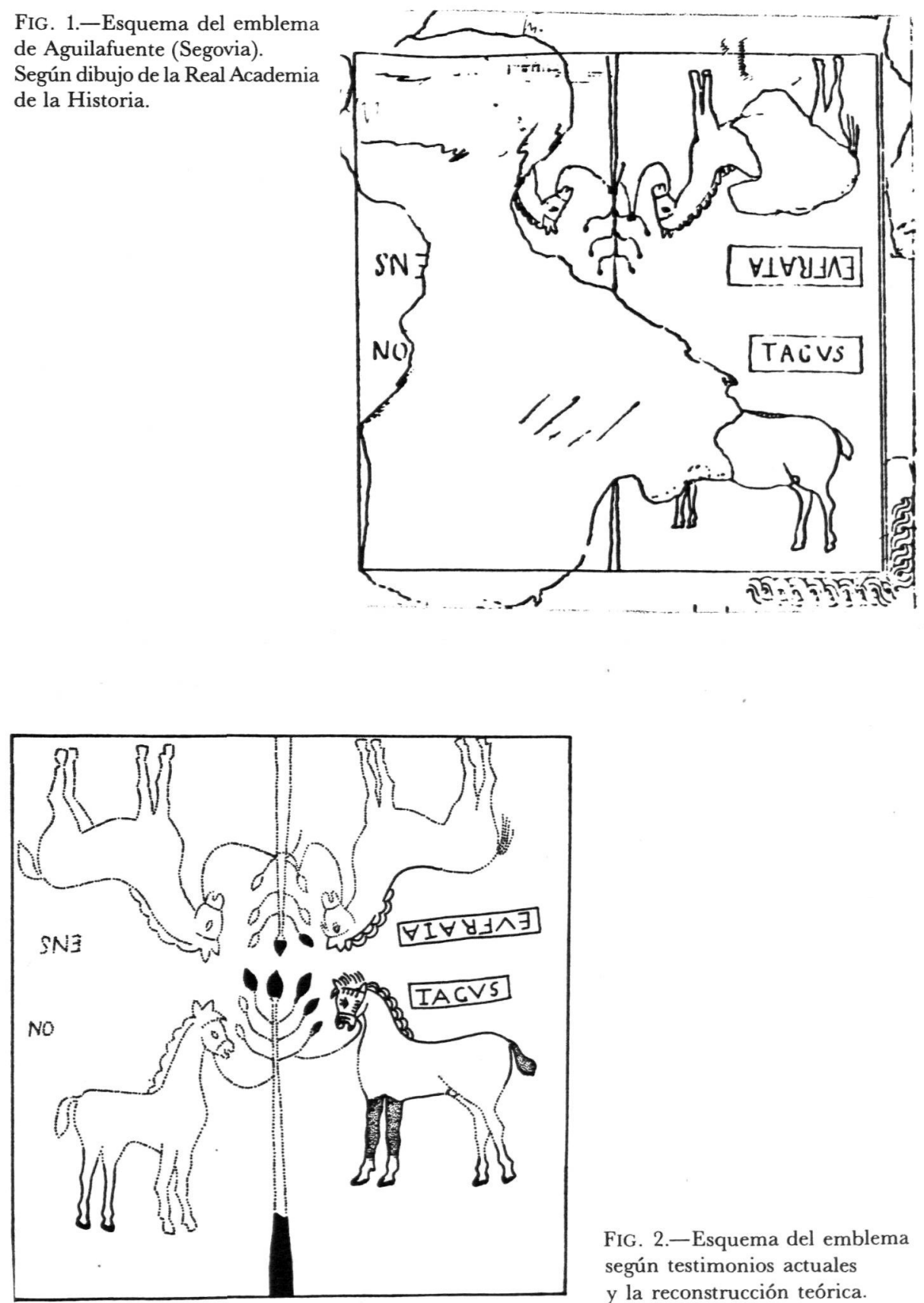

FIG. 2.-Esquema del emblema según testimonios actuales y la reconstrucción teórica. 
ca incluyendo los dos árboles que, situados en el eje de la composición, servían de nexo a cada pareja.

Los caballos se dibujaron de perfil y en reposo. TAGVS, el ejemplar más completo, es de buena alzada, pelaje dorado (teselas amarillo-anaranjadas) y cabeza pequeña muy cuidada en sus detalles. Entreabre la boca y exhibe un llamativo ojo almendrado y vertical con gruesa pupila negra y crecidas pestañas. Carece de bridas, pero el cabezal (capistrum), propio de los animales en descanso o conducidos a mano, está magníficamente representado por teselas rojas aunque el ennegrecimiento de algunas zonas impide precisar claramente algunos detalles. Se distingue la frontalera adornada con borlas (?) y unida con un disco, a modo de phalera, a la testera que pasa por detrás de las orejas y se prolonga en el montante sujeto a la muserola (nasale). Es posible que también se representara la correa del ahogadero y algún otro adorno, hoy confundido con la delimitación de la cabeza y el pelaje. El ronzal o lorum es bien visible y está sujeto por debajo de la mandíbula inferior a otra tira que empalma con la muserola y se dirige hacia el árbol.

Una graciosa guedeja cae sobre la frente y se independiza del tupido penacho o crista bellamente recortado y unido a una espesa crinera, tal vez encintada, arreglada en perfectas ondas bicolores. La cola es lanceolada y voluminosa como si, doblada, estuviera cubierta por una especie de funda roja. Con este mismo color se representaron los robustos brazuelos causando el efecto de estar ocultos por una especie de polainas mientras nudillo, calcañar y pezuñas quedan al descubierto (22).

Otro detalle que llama la atención son los remates de las patas tanto de este caballo como de lo conservado en su pareja. Los cascos se delimitaron con un borde negro que, reforzado por delante, contornea parcialmente la pezuña hasta rematar en pequeñas angulaciones a modo de clavos. Se trata de una especie de «hipposandales encerclantes", próximas a las auténticas herraduras (soleae ferreae), artilugio que no debe extrañar si tenemos en cuenta los datos recopilados por Vigneron (23) y la publicación de Lawson (24) además de la repetición de idénticos remates en el caballo PYROLAMPES, según un «Kontorniat» publicado por los Alföldi (25).

En cartela rectangular roja se enmarca la palabra TAGVS, con capitales negras, encima de la grupa. Se contrapone al nombre de EVFRATA, yegua de la que sólo resta el corto penacho, la ondulada crinera, el mechón entre las orejas y el ojo grande destacado en su pelaje blanco. El dibujo primitivo ilustra que también se detalló el cabestro y que la curva dorsal, más acentuada que la de Tagvs,

(22) Es imposible afirmar si intencionadamente se representó alguna protección de los brazuelos o si se trata de diferenciar el pelaje. Tampoco es fácil concretar si lo que parece el sexo en el dibujo antiguo (erróneamente situado) pudo ser algún tipo de emblema o marca.

(23) No se trata de hiposandalias curadoras. El tipo es diferente al localizado por P. de Palol en Clunia (Homenaje al Prof. Almagro, T. III, págs. 423-428). La protección de los cascos se usó especialmente en terrenos de cierta dificultad y climas fríos. Un estudio detallado de la problemática de estas protecciones, tipos y clasificación según diversos autores en Vignerón, P.: O. c., nota 14, T. 1, págs. 44-50.

(24) Lawson, A. K.: "Studien zum Römischen Pferegeschirr», Jahrb RGM (1978), 1982, págs. 131-140, fig. 3 (distribución espacial de las auténticas herraduras recogiendo los ejemplos españoles).

(25) Alföldi A. und E.: Die Kontorniat-Medaillons, A. Mu. G. S., vol VI, 1976. Núm. de catál. 663, lám. 210, 2. La pieza procede de Novisad, Yugoslavia. 


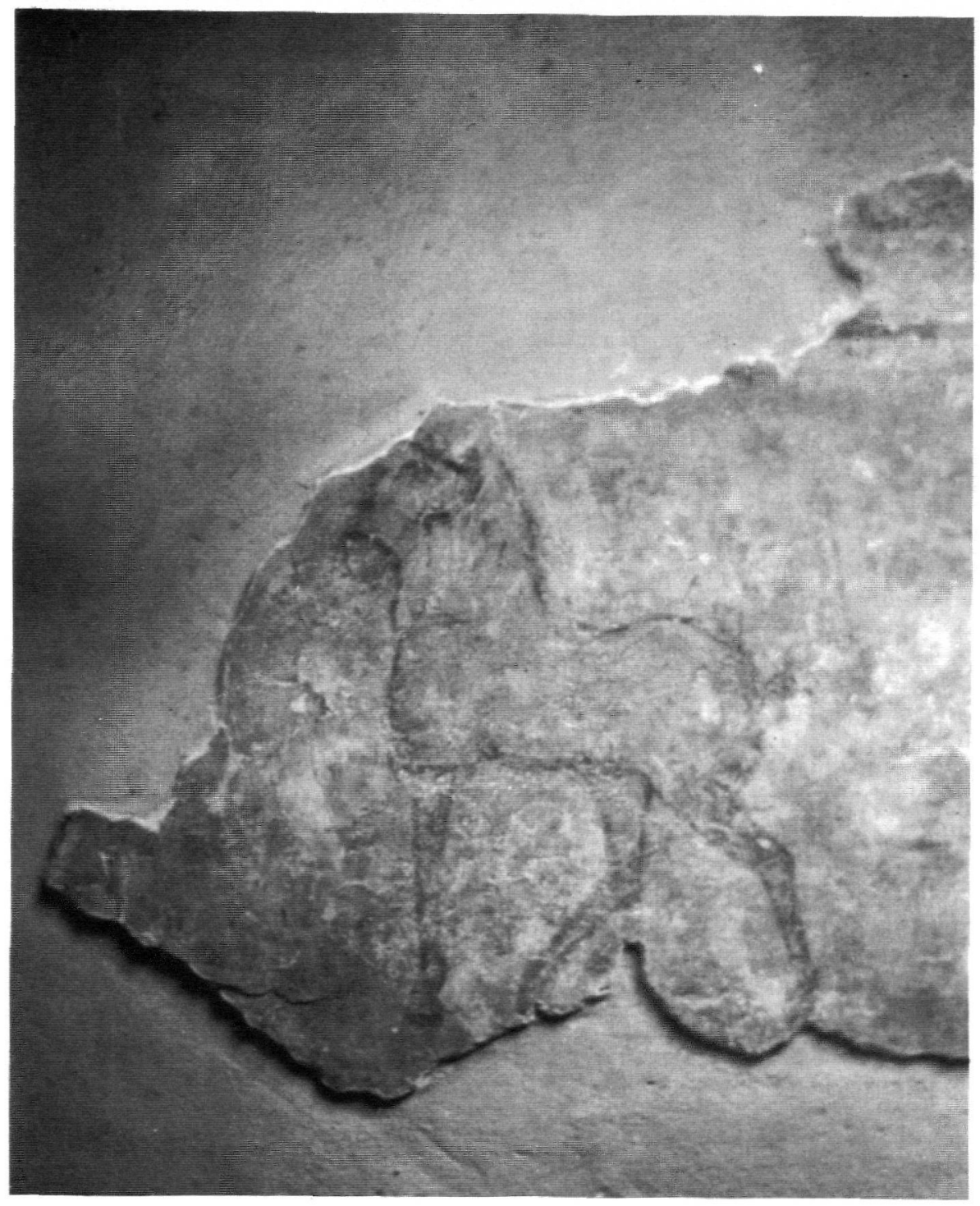

LÁM. I.-Pintura mural de Aguilafuente (Segovia). Detalle. 


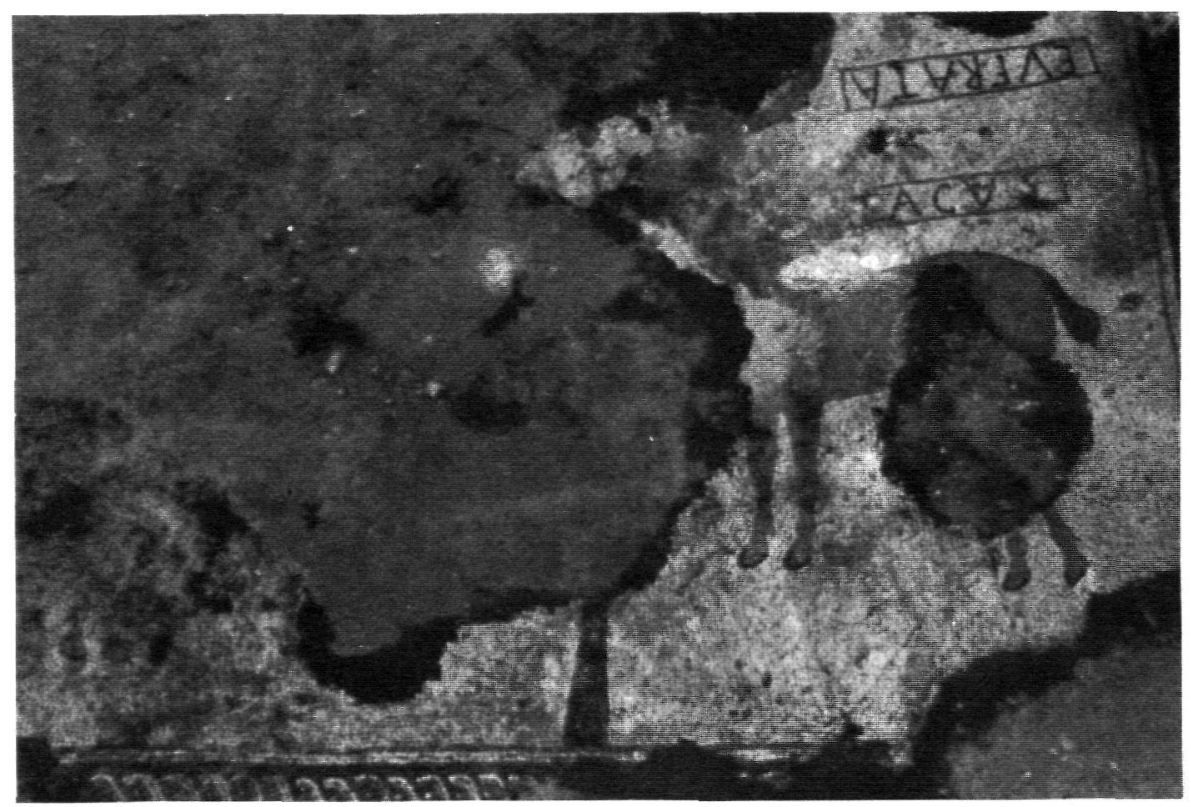

LÁm. II.-Mosaico de Aguilafuente (Segovia) (Detalle).

se prolongaba en una cola rematada en flecos (¿cintas o crines trenzadas?). El ronzal pasaba por la rama más baja del árbol, entonces visible en su totalidad, y se sujetaba al tronco en el mismo punto donde se ataba al animal opuesto del que sólo se conservaba la cabeza (desgraciadamente no consta el color del pelaje). Su nombre, sin cartela, terminaba en ...ENS, mientras el del animal perdido de la primera pareja se iniciaba con las letras NO... (26) libre de cartela (27).

El detalle de los accesorios, en contraste con la tosquedad de la figura completa, demuestra que no se trata de bestias rurales o de transporte sino de cuidados animales comparables en el preciosismo de la cabeza a la excelente representación del mosaico de Dueñas (28) o de los ejemplares del hipódromo. El especial arreglo de crines y penacho, aunque no sea una novedad, tiene su exacto paralelo en los

(26) Estas palabras incompletas fueron erróneamente trascritas por Lecea (vide nota 49) y en nuestra publicación citada en nota 15. La documentación de la Real Academia de la Historia confirma que se trata de ENS y NO.

(27) En los mosaicos africanos los nombres no llevan cartela. En la Torre de Palma las letras son blancas y los fondos de las cinco cartelas son todos oscuros (O. c., nota 8).

(28) De Palol, P.: "Das Okeanos-Mosaik in der romischen Villa zu Dueñas (Palencia)", MM, n. ${ }^{\circ}$, 1967, págs. 196-225 y lám. 4 (en color). 
caballitos que ornan atalajes y elementos de arnés, valga como ejemplo el bronce de Morón de la Frontera (Sevilla) (29).

La imagen de Tagvs encaja plenamente en la estampa ideal -exterior y psicológica - que cualquier buen conocedor de caballos eligiría siempre: cabeza pequeña, crinera espesa, ojos saltones y oscuros, pecho amplio, orejas hacia adelante, cuerpo no ventrudo, grupa y ancas carnosas, cerradas y redondas, patas rectas e iguales con alta horquila y canon destacado... propiedades que, según los tratadistas (30), son muestra de la buena disposición del carácter de estos animales y de su rendimiento en la cabalgadura y la carrera. Incluso cualidades como la briosidad se ha pretendido reflejar en el atenuado entreabrir de la boca, pelaje hirsuto de la cara y en el ligero movimiento de las patas, evidenciando que aun en descanso conserva el ardor de su potencia física.

Estas observaciones y la constatación de caracteres físicos diferenciados llevan, hipotéticamente, a las ocupaciones y aficiones del propietario, incluyendo sus conocimientos de hipología (31). Estéticamente el dibujo es torpe, pero el artistas con más docilidad que ingenio copió formalmente animales reales satisfaciendo con su trabajo la philotinía de quien comisionaba el mosaico.

La ausencia de ramos o palmas impide hablar de caballos campeones, pero su disposición emblemática, a uno y otro lado de este remedo de palmera, no deja de evocar, como opina Ennaïfer para los équidos africanos, la idea del triunfo. La prestancia en el arreglo, el elocuente número de cuatro (32) y la pomposidad de los nombres son otros tantos argumentos en pro de su destino circense.

Entre los numerosos nombres de équidos romanos sólo unos pocos corresponden a ríos. TAGVS se nombra en cuatro "defixionum tabellae" (33) localizadas en tumbas violadas de Hadrumetum. Las largas listas a modo de letanías con la reiteración de la palabra cadant y de fórmulas como ... equos veneti et russei ne currere possint, nec frenis audire possint... palma vincere non possint... indican que las maldiciones de las

(29) Blanco, A.: "El Pasarriendas romano de Morón», AEA, n. * 40, 1967, págs. 99-103, fig. 1. Adorno de cola y crines es idéntico pero la estampa física es distinta. Además lleva ephippium (fechado hacia el año 200).

(30) Citas literarias recogidas por Vigneron (O. c., nota 14, págs. 4-10). San Isidoro (Etym. libro XII, 1, 45-48) hace una descripción parecida. Umberto Eco en su novela El nombre de la Rosa pone en boca de su personaje esta estampa ideal para identificar el caballo del abad.

(31) Aunque la reproducción de cartones llevara a reiterar convencionalismos lo documentado atestigua que cada caballo debía ser un unicum. En el modo de atar los caballos con solo el cabestro se siguen normas hipológicas, pero el arreglo es muy particular y común en España. En Aguilafuente nos comentaron que todavía en las fiestas se encintaban así crines y colas. El tipo de Tagus se aproxima más a los ejemplares denominados "arabes" mientras el corcel de la pintura mural responde a la raza "bárbara". Para estas clasificaciones referencias en el artículo cit. de Ennaĩfer (nota 3).

(32) El número de cuatro hace referencia a los caballos del sol y a los de las cuádrigas y también a las estaciones y a las facciones del circo. Discusiones sobre el simbolismo en Dunbabin, O. c., notas 1 y 2. Para esta autora las representaciones de cuatro caballos son más antiguas que las de dos o uno (nota 1 , pág. 103).

(33) Audollent, A.: Defixionum Tabellae, Frankfurt, (reimp.), 1967, n. ${ }^{\circ}$ 275, línea 16; n. ${ }^{\circ}$ 276, línea 18; n. 282 a $13 ;$ n. 284,12 ). 
planchuelas de plomo se lanzan contra una serie de corceles de las facciones azules y rojas que, junto a Tagvs, competían en el circo de Susa.

El mismo nombre se grabó en una pieza calada de arnés de procedencia hispana conservada en la colección Jules Sambon de París y que exhibe un caballito con crines y cola arregladas a la manera de Aguilafuente (34).

El nombre de EVFRATA coincide con el de la yegua enganchada al yugal izquierdo de la tercera cuádriga participante en la carrera del mosaico circense de Barcelona (35). El nombre corresponde al femenino de Eúfrates en la versión de fuente, tal y como se interpreta en la inscripción de la basílica de Ostia (36).

No es fácil identificar los nombres de los otros dos caballos y sólo cabe decir que ninguno de ellos se ajusta a los ríos elegidos como nomina equorum (37).

\section{Análisis y explicación del tema}

La estructura general del mosaico de Aguilafuente adapta en su iconografía el esquema de dos de los pavimentos de la casa de Sorothus, justamente en Hadrumetum (38).

El inventariado con el núm. 57.120 ofrece cuatro medallones en las esquinas. Cada uno contiene una pareja de corceles libres de ataduras flanqueando una palmera con frutos. Están adornados como los de carreras y exhiben atributos de victoria. Nombre sobre el lomo, marca y nombre del propietario (Sorothi) demuestran que a la par que se honra a los nobles animales se da información del dueño de la cuadra. Además en el centro del emblema se especifican las actividades rurales mediante un paisaje de vasto horizonte donde pastan los caballos en libertad no lejos de la villa.

(34) De Palol, P.: "Algunas piezas de arnés de época tardorromana e hispano-visigoda", AEA, n. ${ }^{\circ}$ 125, 1952, pág. 311, fig. 5, 21).

(35) Balil, A.: "Mosaicos circenses de Barcelona y Gerona", Bol. RAH, n. ${ }^{\circ}$ 150-151, 1962, págs. 280 y pasim.

(36) Calza, G. y Becatti, G.: Ostia, Roma, 1975, pág. 47. En el arquitrabe se lee: IN CHRISTO GEON FISON TIGRIS EVFRATA CRISTIANORVM SVMITE FONTES (mención a los cuatro ríos del paraíso en relación con las fuentes cristianas $\left(2{ }^{a}\right.$ mitad del s. IV). A pesar de las sospechas sobre la posibilidad de que la villa de Aguila fuente se hubiese transformado en basílica o estuviera relacionada con el culto cristiano con anterioridad a su reutilización como necrópolis visigoda no se ha descubierto, hasta la fecha, ningún testimonio que lo confirme.

(37) En los nombres conocidos las posibilidades de iniciar con NO son limitadas (Vide Salomonson, O. c., n. ${ }^{\circ}$ 106). La inscripción n. $^{\circ} 10056$ del CII, VI, procedente de Roma y alusiva a las vicorias de un auriga anónimo con cabellos de distinta procedencia, cita entre los hispanos los nombres de NOBILIS, NOTATVS y NORICVS (este último nombre según Ruggiero en Dizionario Epigrafico, Roma, 1961. 2155 (equus) hace referencia al campo de entrenamiento de caballos). Comentario a la inscripción en Piernavieja, P.: "Los juegos de circo en la España Romana", Citivs, Altivs, Fortivs, T. XVI, 1974, pág. 259. La terminación ENS denota cualidades y las posibilidades son numerosas: CLEMENS, POTENS, VALENS... Cabría la posibilidad de nombres de vientos. NOTVS y ORIENS se llaman los lebreles del mosaico de la villa de los Baños de Valdearados (Burgos).

(38) Foucher, L.: O. c., nota 7, Id. Hadrumetum, París, 1964, págs. 245 y ss. 


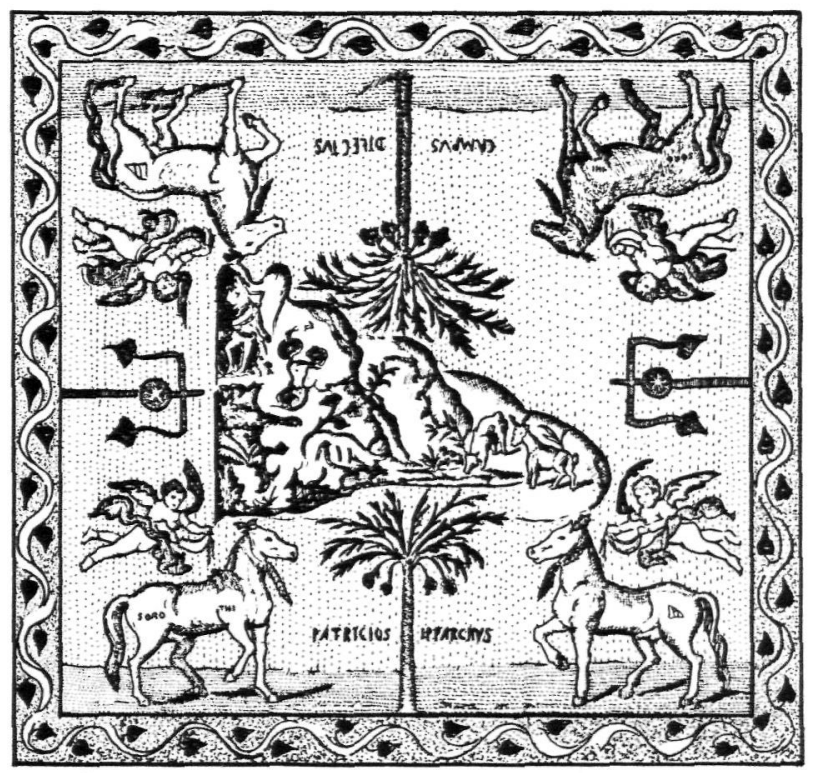

Fig. 3.-Mosaico de la Casa de Sorothus en Hadrumetum (Inv. n. ${ }^{0} 57.113$ de L. Foucher). Museo del Bardo (Según fotografía).

El mosaico n. 57.113 (fig. 3) se aproxima más a Aguilafuente. Sendos árboles actúan de eje de una doble pareja contrapuesta con cuatro puntos de mira. En los laterales cuatro fascinas rematadas en hojas de hiedra remarcan el triunfo al igual que los amorcillos situados sobre el lomo de los animales. Los nombres de los caballos colocados delante y la presencia de marcas e identidad del propietario reiteran la información anterior incluyendo en el centro del emblema un bucólico paisaje evocador del campo ganadero. Muchos investigadores coinciden en interpretar las escenas rurales de ambos pavimentos como el traslado a la ciudad de la realidad económica de Sorothus cuyo latifundio, dedicado prioritariamente a la cría de caballos, se identifica con el Saltus Sorothensis (39).

El mosaico de la Casa del Tripholium de Dougga (40) insiste en el mismo esquema con ligeras variantes. Las parejas se oponen, llevan en la boca las ramas de la victoria, nombres y arreglo son propios de los caballos de circo... pero los árboles axiales se han sustituido por la escena de un erote cazando una liebre con red entre tupido follaje, clara alusión al esfuerzo por el triunfo.

(39) Nota 38, págs. 214 y Dunbabin, o. c., nota 1, págs. 113. Las posesiones se sitúan en la región de Souk-Ahras en donde se halló una inscripción que menciona el saltus sorothensis.

(40) Dunbanbin: Nota 1, págs. 102, fechado en la 1/2 del s. III. 
A pesar de estos paralelos hay que señalar las particularidades de Aguilafuente. La palmera se sustituyó por un árbol más familiar, posiblemente un laurel, y aparte de detalles ya comentados, la diferencia más notable radica en que los animales están atados al tronco vegetal como en los ladrillos andaluces. Esta atadura se aproxima a las representadas en seis mosaicos africanos que documentan la disposición tripartita utilizando, en cuatro casos diferentes, el «símbolo del premio» (una especie de columnilla) como elemento intermedio (41).

La auténtica significación de la atadura nos la proporciona el mosaico de POMPEIANVS (Cirta, Constantina) quien hizo representar la arquitectura de su fundus con seis caballos dispuestos en registros superpuestos (fig. 4) atados a un pilón o pesebre con un simple cabestro (siguiendo los consejos de Jenofonte Eq, V,4) y, a juzgar por las muchas representaciones, este sencillo elemento (al igual que en los caballos de Aguilafuente) atestigua los inicios de la doma (42). La entrañable frase Vincas non vincas te amamus Polidoxe indican que por encima de todo premio se sitúa el amor y los desvelos por el noble bruto. Escenas como las de los cuatro palafreneros entrenando otros tantos caballos en un mosaico de Susa, fechado en el s. III (43) o las de la villa italiana de Baccano (44) y la de la pintura de Mérida (45) reafirman este interés por especificar la doma y el ejercicio.

Esta hipótesis debe complementar al sentido de triunfo de los mencionados ladrillos de la Bética (fig. 5) pues se añadió a la composición una especie de valla en la que se encajan las patas de los animales. Aunque la altura sea escasa la "barrera" se asemeja a las que aparecen en la estructura del circo o, aisladas, tal y como se dibujó en el cuadro núm. 35 del Mosaico de Los Caballos como símbolo de la carrera (46). Este aprendizaje de docilidad también se explicita en la placa cerámica de Hoyo de Bélmez (Córdoba). Representa un jinete que frena al noble bruto cuyo cuerpo se cubre, al igual que en las piezas anteriores, con una especie de gualdrapa, similar a la de los caballos de Pompeianus, y tiene las patas situadas a un

(41) Ennaïfer: O. c., nota 3, recoge los siguientes ejemplos de caballos atados al símbolo del premio: Casa de Ariadna, Cartago. Fundus Bassianus, Sidi Abdallah en Bizerta. Moknine en Sahel (Túnez). Lahmimine en Limisa (Ksar Lemsa, Cartago). Este último ejemplo envuelto en una atmósfera comparable a la pintura mural de Aguilafuente. Se fecha s. V.-VI d. C.

(42) Procede de Oued-Athménia (Cirta): Dunbabin o.c. nota 1, pág. 94 y A. Berthier, «Etablissments agricoles antiques à Oued-Athmènia”, Bull. Arch. Alg. 1962-65, págs. 7 a 20 del núm. 1.

Los tratadistas griegos y romanos, al igual que en la actualidad, aconsejan iniciar la disciplina de la doma mediante el cabestro (Vigneron, o. c., nota 14, pág. 59). Trenzar las crines es parte de la iniciación y también palmear cariñosamente brazuelos, cuello y cabeza. El gesto del tacto se documenta en representaciones prerromanas y romanas.

(43) Ennaïfer: O. c., nota 3, fig. 5 y Foucher: O. c., nota 7, Inv. n. ${ }^{0}$ 57.211, lám. XLIX.

(44) Becatti, G. et alii: Mosaici antichi in Italia. Reg. Sep. Baccano villa romana, Roma, 1970, n. ${ }^{\circ}$ 26-29, láms. 22-25. Aquí y en el mosaico anterior se incluye en la doma una yegua, más difícil de carácter que los machos $\mathrm{y}$ de resultados inciertos.

(45) Abad, L.: Pintura romana en España, Univ. de Alicante, 1982, págs. 347; Alvarez y Saenz de Buruaga, J. M.: "Una casa romana con valiosas pinturas", Habis, n. $5,1974$.

(46) SALOMONSON: O. c., nota 6, fig. 39, lám. VI. El nombre sugerido puede ser CVRSOR, DROMONO, CALLIDROMVS... 


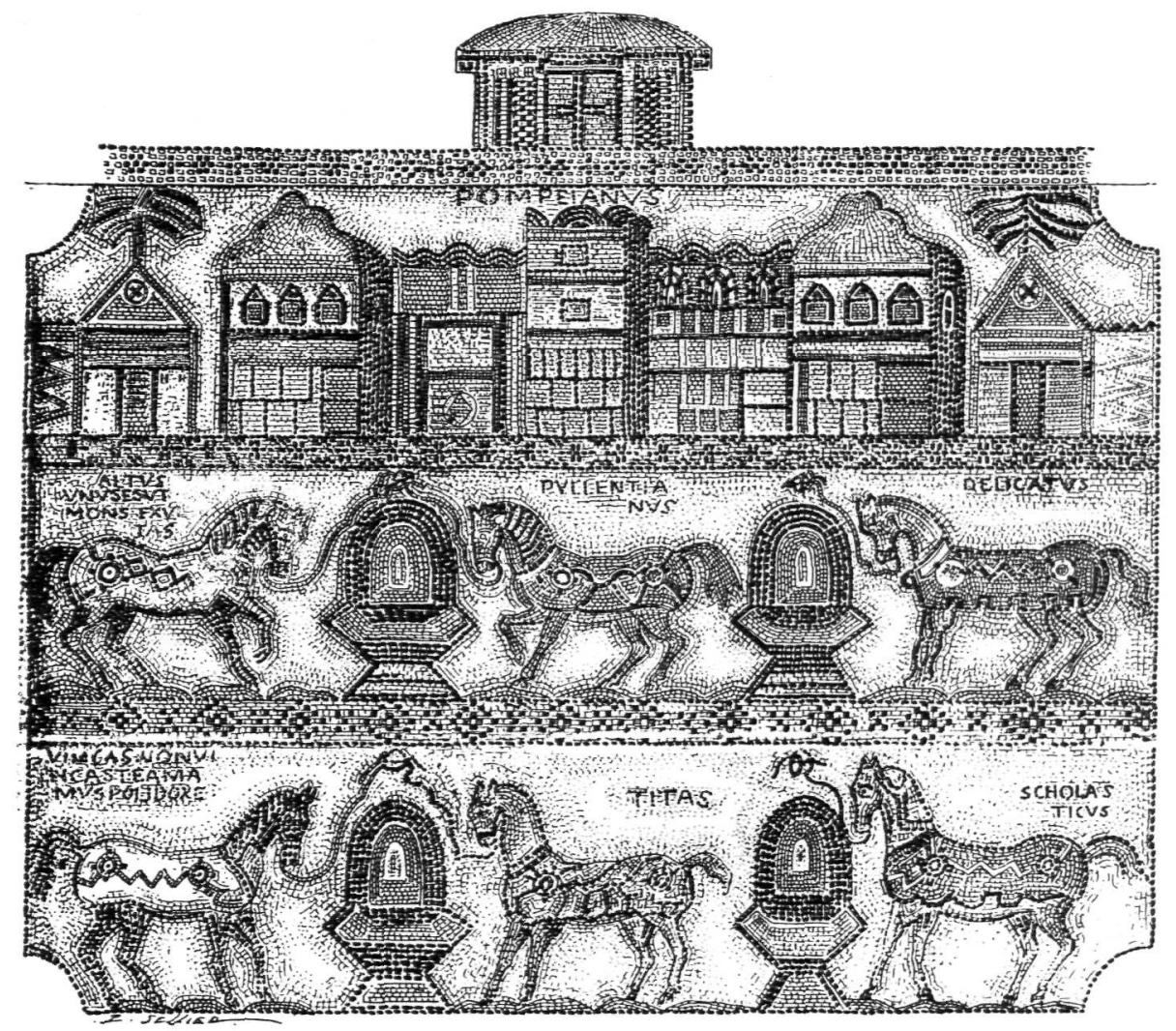

Fig. 4.-Mosaico de Oued Athménia (perdido). Según fotografía.

lado y otro de una vara tendida en el suelo. Además un sirviente le "palmea" el pescuezo (47).

Esta evocación de la doma y crianza explica la intención del caballo de Dueñas y la de tantos équidos de los mosaicos hispanos, con o sin ronzal, insertados en escenas órficas y en imágenes aparentemente desconectadas de cualquier actividad más específica.

Volviendo a la temática circense y su relación con las villae, la teoría de Humphrey (48) sobre la celebración de carreras en hipódromos no monumentales y con aforo más restringido es ciertamente lógica y presupone disponer de campos adecuados donde se probarían los animales antes de las competiciones más espectacu-

(47) Palol: O. c., nota 11, pág. 269 y lám. LX, 2.; Porras, A.: El caballo y su doma, Lucena, 1980, págs. 137-138, dice que para enseñar el salto se obliga a pasar por unos palos tendidos en el suelo.

(48) Humphrey: O. c., nota 1, págs. 331-333 y 384-387. 
lares. En Monte Maior, no lejos de la villa de Torre de Palma, existió un pequeño circo y aunque sea un mero supuesto debo recordar que en 1868 cuando se descubrió el mosaico de Aguilafuente se informaba de la existencia de una hondanada denominada "Cerco de Roma», tal vez corrupción de la palabra "circo" (49).

Es obvio que aun cuando los corceles destinados al circo proporcionaran a los latifundistas buenas ganancias, no todos los animales alcanzaban esta meta. Equus venator fue, a nivel privado, tan preciado como equus circensis o el usado por los equites. Piazza Armerina (50) es un buen muestrario de estas funciones y de un tipo de vida que se intentaba emular.

De lo expuesto se pueden extraer una serie de conclusiones que enlazadas entre sí y valorando los paralelos y las relaciones pintura mural-mosaico, así como su situación en el conjunto arquitectónico de la villa, abogan por identificar a los caballos de Aguilafuente como corceles de intención circense, insertando el lenguaje visual con el programa temático del ciclo de los latifundia (51). El dueño informaba en la habitación principal, al entrar a la casa, que el cuidado de los caballos era la actividad más digna, orgullo de sus actividades. La alusión al premio o al triunfo, en sentido lato, es una interpretación complementaria y concuerda plenamente con la idiosincrasia de un estilo de vida a la que se vincula Aguilafuente a lo largo del siglo IV.

El esfuerzo en la doma y entrenamiento, al igual que la competición ecuestre, el triunfo sobre el enemigo, la habilidad en la caza... son proezas que encajan, alegóricamente, en el concepto de "virtus" (alcanzar con esfuerzo una meta) y preludian la "apoteosis» tras el curso de la vida. La utilización simbólica y apotropáica de este género de imágenes, su traslado al plano funerario y su adaptación al repertorio cristiano, son eslabones de una cadena de conceptos polivalentes de larga tradición y enraizamiento.

\section{Origen del tema}

L. Foucher al estudiar los mosaicos de Sorothus se hacía eco de los trabajos de Leglay y consideraba como antecedente directo del tema las estelas romanas consagradas a Saturno, siguiendo la tradición fenicia asumida por los cartagineses (52). Ennaïfer por su parte, insiste en el carácter "verosímilmente africano" y coloca la representación tripartita en el contexto simbólico de la victoria, tomada de los juegos de circo y de la relación entre el triunfo y la palmera, idea que con matiz dife-

(49) De Lecea, C.: "Los mosaicos de Aguilafuente» en Miscelánea Bibliográfica-literaria y Variedades Segovianas, Segovia, 1915, pág. 26.

(50) Gentili, G. V.: La Villa Erculia di Piazza Armerina. I Mosaici Figurati, Roma (s.a.); Carandini, A.: "La villa di Piazza Armerina. La circulazione della cultura..." Dialoghi d’Arch. 1, 1967, págs. 93-120.

(51) Grabar, A.: «Programmes iconographiques á l'usage des propiétaires des latifundia romaines», Cah. Arch. 1960-62, n. ${ }^{\circ}$ XI-XII, págs. 394-395.

(52) Foucher: O. c., nota 38, pág. 246. 


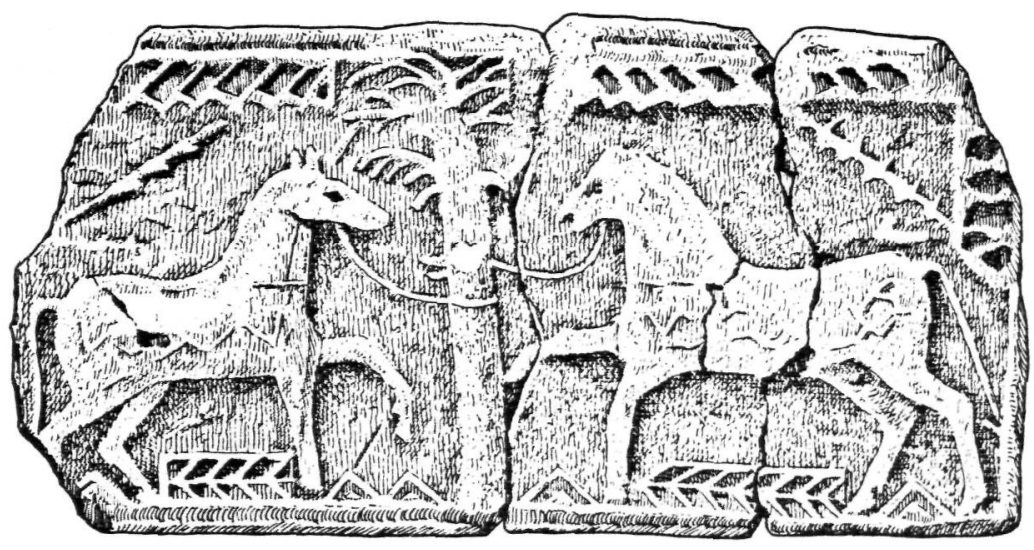

FIG. 5.-Ladrillo de Osuna. (Colección Fajardo). Según fotografía.

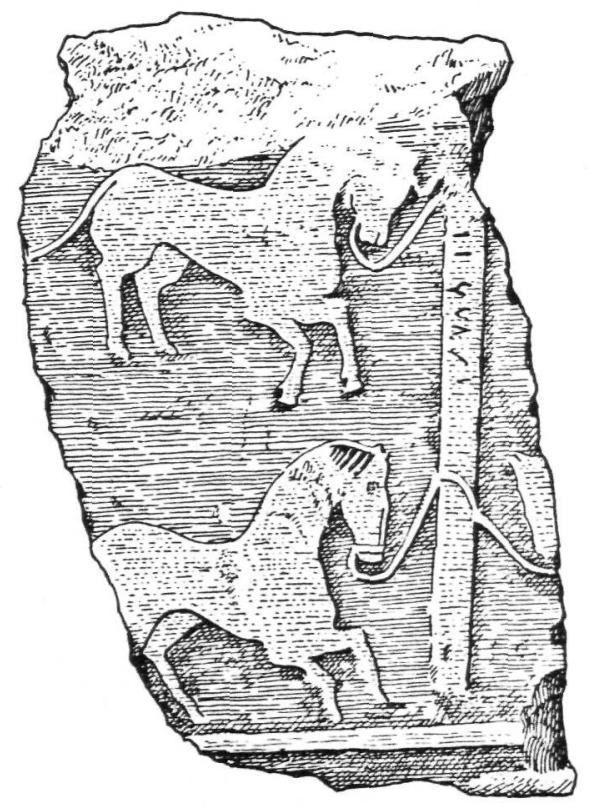

FIG. 6.-Relieve con inscripción ibérica procedente de La Vispesa. Museo de Huesca. Según fotografía. 
rente es considerada por $\mathrm{M}$. Yacoub quien ve en el esquema una síntesis realizada en Africa entre el tema del "Arbol de la Vida" y el de los Dioscuros (53).

A este respecto hay que recordar que en la Península Ibérica los esquemas heráldicos son frecuentes desde la etapa orientalizante. El "árbol de la vida» se sitúa en el centro separando los animales, afrontados, y aún cuando los eq́uidos no sean comunes al repertorio, la España prerromana ofrece un sin fin de figuraciones con caballos, sin faltar su asociación a una palmera (54).

Las representaciones de despothes o potnia theron con la divinidad como eje siguen fielmente el esquema tripartito, documentando incluso la presencia excepcional de cuatro caballos en el relieve del Llano de la Consolación (Albacete) y la modalidad de contraponer prómotos de équidos en camas de bocado (p. e. Cancho Roano, Badajoz) (55). Este tipo de composiciones además de sugerir la idea de domesticar y proteger a los caballos incorpora en su intención el concepto de victoria o triunfo como se desprende por el destino funerario de algunas piezas y por las figuraciones que sustituyen a la divinidad por un guerrero (p. e. monumento barcelonés de Malla, Osona (56) adelantándose a la iconografía romana que coloca al auriga vencedor, a pie, entre caballos laureados.

En esta línea de antecedentes cabe citar uno de los relieves de Vispesa (Tamarite de Litera, Huesca) (57) con cuatro caballos superpuestos y atados dos a dos a un poste o estaca central (fig. 6) y la celebración de agonothetes (p. e. las carreras del relieve de Illescas (Toledo) (58) con anterioridad al mundo romano a quien debemos la institucionalización y normativa de las competiciones y el marco monumental (59).

Es obvio que la larga trayectoria temporal y espacial de las representaciones equinas responde al significado trascendental de estas imágenes, plenamente justi-

(53) Ennaïfer: O. c., nota 3, págs. 842-843 y nota 127.

(54) Almagro Gorbea, M. y Rubio, F.: "El monumento ibérico de "Pino Hermoso"'. Orihuela, Alicante», TP. n. ${ }^{\circ} 37,1980$, págs. 345-362.

(55) Blázquez, J. M.: “Dioses y caballos en el mundo ibérico» en Imagen y Mito. Madrid, 1977, págs. 291-306. Maluquer, J.: El santuario ibérico de Zalamea de la Serena, Badajoz, Barcelona, 1981, págs. 100-109, fig. 37. Pérez González, C. y Fernández Ibáñez, C.: Tres nuevas piezas de arnés tardorromanos», Arqueología, n. ${ }^{\circ} 13$, (Porto), 1986, págs. 180-184. Interesan las piezas n. 2 (con dos prótomos de équidos) y n. ${ }^{\circ} 3$ (rueda con cuatro caballos). El esquema está en la línea de las piezas prerromanas. El artículo contiene bibliografía de estos bronces en el mundo romano.

(56) López, A. et Alii: Monument funerari iberic de Malla, Dip. Barcelona, 1986, p. 17. En los contextos funerarios la muerte se considera la meta en la carrera de la vida. Vide nota 19, sobre esta idea.

(57) Beltrán, A.: "La inscripción ibérica de Binéfar en el Museo de Huesca», IX, C.N.A. (Mérida, 1968), Zaragoza, 1970. págs. 518-522. La pieza parece de naturaleza diferente a las que conforman el llamado monumento de Binefar. Tiene una inscripción ibérica a lo largo del poste, muy perdida. El yacimiento de La Vispesa perduró hasta el s. II d. C.

(53) Balmaseda, J. L. y Valiente, S.: “El relieve de Illescas», AEA, n. ${ }^{\circ}$ 54, 1981, págs. 215-234.

(59) Humphrey: O. c., nota 1, cap. 7, recoge amplia documentación de los testimonios circenses en España. También Piernavieja: O. c., nota 37. En la tabla de bronce de Gallur (Zaragoza) los ludi organizados privadamente por Sexto Aminio para los pagos de los "gallos" y "sergadinenses" pueden hacer referencia a este tipo de competiciones (?). Beltrán, M.: “Una celebración de Ludi en territorio de Gallur», XIV, C.N.A. (Vitoria, 1975), Zaragoza, 1977, pág. 1.061. 
ficado por la repercusión social y económica de estos animales en nuestro territorio (60).

Estas puntualizaciones tan someramente esbozadas sirven para matizar los antecedentes iconográficos, valorando en su justa medida la influencia africana y la difusión de unos modelos integrados en la ideología de una época, capaz de revitalizar y dar nuevo sentido a conceptos muy viejos, comunes al acervo mental de las poblaciones asentadas en ambas orillas del Mar Mediterráneo.

(60) Lucas-R. Rubio, I.: "Introducción del caballo como animal de montura. Problemática». Col. Int. sobre la $I^{a}$ Edad de Hierro, Salamanca, 1984 (en prensa). Las fuentes escritas referentes a estas cuestiones han sido tratadas en numerosos artículos por Blázquez, J. M. y de Palol, P. y Balil, A. Vide también los comentarios de Humphrey: O. c., nota 1, págs. 441 sobre la Expositio Totius Mundi et Gentium y las referencias a las cartas de Symmachus (p. 461). Si la hipótesis formulada en este artículo es cierta la correspondencia de Symaco entraría dentro del mecanismo normal del "tráfico" de caballos sin que ello presuponga la existencia de grandes yeguadas en todos los establos. Más comentarios en Arce, J.: "Los caballos de Simmaco», Faventia, n. ${ }^{\circ} 4$, 1982, págs. 35-44. 